\title{
O Início de uma Nova Era? Análise Exploratória a Plataformas Digitais de Verificação de Fake News
}

\author{
Fábio Ribeiro \\ UTAD; CECS - Universidade do Minho - fabiofonsecaribeiro@gmail.com
}

Daniela Fonseca

UTAD; Labcom - UBI - dfonseca@utad.pt

\begin{abstract}
Resumo
A política tornou-se num dos principais instigadores do fenómeno mediático amplamente designado por "notícias falsas", especialmente desde a eleição de Donald Trump em 2016 (Figueira \& Oliveira, 2017; Albright, 2017). A popularização deste termo no espaço público também foi acompanhada pelo crescente interesse dos académicos. Por exemplo, hoje discute-se até que ponto a emergência de conteúdos falsos ou manipulados pelos média determina o distanciamento dos cidadãos dos meios de comunicação tradicionais (Tandoc, Zheng \& Ling, 2017; Cádima, 2018). Este

artigo procura estudar o terreno tecnológico da desinformação, através de uma amostra não-probabilística definida por conveniência (Quivy \& Campenhoudt, 1992) e de análise manifesta e latente de factos sociais e mediáticos (Bengtsson, 2016), focadas em diversas plataformas digitais desenhadas para combater as notícias falsas, como Checazap, Fátima, NewsGuard, Polígrafo e Snopes. Os resultados sugerem que a maioria dessas plataformas ainda enfrenta um problema de visibilidade pública, apesar das diferentes possibilidades de relatórios e confiabilidade.
\end{abstract}

Palavras-chave: Notícias falsas, tecnologias, média, jornalismo, desinformação.

\section{The Beginning of a New Era? Exploratory Analysis of Fact Checking Platforms Towards Fake News}

\begin{abstract}
Politics have been the fundamental trigger for the recent dissemination of the expression "fake news", especially since Donald Trump was elected, in 2016 (Figueira \& Oliveira, 2017; Albright, 2017). Following the popularization of this concept, academics seem to be keen in the analysis of such phenomenon. In this sense, scholars have been studied if biased or false

content promoted by journalists often lead to some citizens' disbelief towards the mainstream media (Tandoc, Zheng \& Ling, 2017; Cádima, 2018). This article seeks to address the technological terrain of misinformation, using a non-probabilistic sample defined by convenience (Quivy \& Campenhoudt, 1992) and a manifest and latent analysis of social and
\end{abstract}


O Início de uma Nova Era?

Análise Exploratória a Plataformas Digitais de Verificação de Fake News

media facts (Bengtsson, 2016), focused on various digital platforms designed to combat false news, such as Checazap, Fátima, NewsGuard, Poligrafo and Snopes. The results provided by this critical assessment suggest that most of these platforms are still lacking of a wider public attention, notwithstanding potentialities and innovative perspectives to learn from troubling websites.

Keywords: Fake news, technology, media, journalism, disinformation.

\section{BREVES CONSIDERAÇÕES HISTÓRICAS SOBRE NOTÍCIAS FALSAS}

Em 2019, Kamil Mrozowic, um empreendedor social, quis construir na sua cidade natal, Jedwabne, na Polónia, uma livraria comunitária. Esta pequena e pacata localidade foi subitamente transformada num dos palcos do terror da $2^{\text {a }}$ Guerra Mundial, quando os nazis a escolheram como um dos locais prediletos para assaltar e executar grande parte da comunidade judaica que ali residia, em 1941. Praticamente oitenta anos depois destes traumáticos acontecimentos, o jovem Kamil quis incentivar a discussão sobre o passado tenebroso daquela cidade, sem filtros, nem preconceitos - apenas conversar, com os locais, o que tinha acontecido, num espaço público, aberto a todos, no meio de livros. O jornalista Miguel Carvalho publicaria na revista Courrier International os ecos desta história, resumindo-a de um modo muito concreto: "a ideia de Kamil durou apenas um minuto e esfumou-se mais rápido do que um fósforo" (2018, p. 98). Os habitantes receberam a notícia com incredulidade e não quiseram participar na iniciativa. Muitos argumentaram que não fazia sentido desenterrar memórias passadas, outros preferiram ignorar um assunto que apenas traria má fama à cidade. O sonho de Kamil não se concretizou. "Hoje é muito fácil alguém perder-se entre a verdade e a mentira", lamentou. Com esta iniciativa que não passou de um projeto, Kamil acredita que debater o passado tenebroso das sociedades é essencial para se evitar a manipulação de factos históricos, de modo a evitar a expansão de certos movimentos negacionistas como aqueles que têm acontecido com o Holocausto.

Definir a realidade como "verdade" ou "mentira" supõe todo um debate filosófico que não integra os objetivos deste artigo. O viés complexo entre estas duas suposições integra uma grande quantidade de argumentos que tendem a considerar "notícias falsas" como uma expressão modernizada. Contudo, não faltam exemplos, historica- 
mente considerados, que relatam episódios falsos promovidos pelos média. Apesar de ser possível encontrar preocupações com as notícias falsas no século XIX, sobretudo a partir da emergência da imprensa sensacionalista conhecida por penny press e yellow press (Kovarik, 2011), alguns episódios recentes em torno de grandes conflitos armados, à escala mundial, tornaram a manipulação da informação como um assunto francamente relevante. neste sentido, as duas guerras mundiais foram tremendamente intensas em termos de propaganda, bem como na Guerra do Vietname (1955-1975). A ofensiva dos EUA, em 2003, no Iraque, apresentou dramaticamente ao mundo o chamado Ministro da Informação de Saddam Hussein - Mohammed Saeed al-Sahhaf - enquanto tentava negligenciar as operações militares norte-americanas que estavam a decorrer naquele país. Este caso integra, aliás, o livro de 1921 de Marc Bloch, Réflexions d'Un Historien Sur les Fausses Nouvelles da Guerre, em que o autor francês apresenta inúmeros exemplos de como várias políticas de informação enganosas foram executadas durante conflitos em todo o mundo.

Uma das contribuições mais importantes sobre a ontologia das notícias falsas foi o relatório "O problema das notícias falsas", apresentado por Clarence K. Streit, na Assembleia da Liga das Nações, a 1 de novembro de 1932. Streit, que na altura era o responsável pela Associação Internacional de Jornalistas Credenciados na Liga das Nações, disse que todos os jornais deveriam apoiar, sem margem para qualquer dúvida, uma "política editorial baseada nos factos" (Ribeiro \& Teixeira, 2018, s/p). Streit, que nessa época era correspondente do The New York Times em Genebra, na Suíça, lembrou que as primeiras palavras a serem impressas na famosa imprensa de Gutenberg foram fiat lux - «e então veio a luz». Streit mencionou que as notícias falsas não operam isoladas no campo da desinformação: conversas privadas e os rumores interferem diretamente neste processo. Por fim, Streit destacou que o jornalismo deve ter cuidado com as fontes de informação. $\mathrm{O}$ valor e a responsabilidade das notícias são decisivos para o consumo dos meios de comunicação, sugeriu Streit.

Além desta discussão sobre alguns apontamentos históricos em torno das notícias falsas, é provavelmente mais relevante continuar com outro tipo de debate. O verdadeiro problema relaciona-se, eventualmente, com a definição exata do que está em jogo para as redações e as consequências para o público que lida, inevitavelmente, com notícias falsas. Isso supõe uma avaliação sobre a forma como os cidadãos se relacionam com os fatos.

Durante uma recente entrevista no El País, Noam Chomsky argumentou que a sociedade já não acredita em factos. Chomsky mencionou que a criação de "factos 
alternativos" é crucial para determinar até que ponto as pessoas se conseguem posicionar quando se trata de crenças. O cientista explicou que esta falta de confiança decorre de uma ampla descrença nas instituições públicas, incluindo políticos e os média. "As pessoas geralmente sentem-se sub-representadas, por causa dos seus empregos precários, por exemplo. Isso leva a um sentimento de raiva, medo e de fuga à realidade dura do quotidiano", disse Chomsky (Ahrens, 2018). José Gil, um dos filósofos mais destacados em Portugal, centrou o "populismo", como ideologia política, no processo de fabricação de notícias falsas (Céu e Silva, 2019): "os critérios para observar a realidade e a sua veracidade foram desmantelados (...) o carisma natural e a identificação do discurso parece ser mais decisivos que a notícia”. Na verdade, estes depoimentos reforçam uma das linhas atuais da investigação na área de interseção entre o público e os média, sobretudo na aferição da confiança dos cidadãos perante estas instituições, que tem demonstrado sinais preocupantes (Melro, 2019; Parente, 2019; Marinho, 2000). Risto Kunelis, investigador da Universidade de Helsínquia, na Finlândia, recentemente apontou alguns aspetos decisivos no consumo dos média (Borges, 2019): "os cidadãos estão totalmente sujeitos a bolhas de informações falsas e enganosas, onde as opiniões são apresentadas como factos, fornecidas por anúncios segmentados de maneira preocupante. Esta é uma ferramenta massiva para a eficiência da desinformação".

\section{O PAPEL DA INTERNET COMO FERRAMENTA DE POPULARIZAÇÃO DO TERMO "NOTÍCIAS FALSAS"}

A popularização da expressão "notícias falsas" na atualidade mediática relaciona-se inevitavelmente com o destaque que o contexto político tem dedicado a este tema (Cram, 2019). Provavelmente, a disseminação deste conceito tem vindo a impor-se em detrimento de uma certa sistematização em torno do mesmo e o consenso nas abordagens dos académicos parece dispersar-se. Katsirea (2018) responsabiliza as revelações feitas pelo site Buzzfeed, sobre alegadas interferências russas nas eleições americanas de 2016, para justificar a emergência do fenómeno.

A popularização do termo convive com a abrangência em considerar como "notícias falsas" uma série de aspetos que visam denunciar a utilização de falácias ou informações claramente falsas como parte do discurso público, político e mediativo. Neste sentido, num relatório de 2018, a Comissão Europeia sugere que se utilize o termo 
"desinformação" para designar todos os conteúdos propositadamente utilizados para manipular, distorcer ou falsear a realidade. Precisamente neste sentido, Claire Wardle e Hossein Derakhshan (2018) definiram sete tipos de conteúdos no conceito de "desordem informativa”: sátira ou paródia (não existe qualquer intenção de ferir suscetibilidades, mas a mentira pode estar presente); enviesamento (sobre personalidades e instituições); manipulação de fontes de informação (utilizando declarações falsas); fabricação autónoma de conteúdos falsos (informações novas e recentes destinadas a enganar propositadamente); relações causais falsas (entre aspetos da realidade, desconexos entre si); contextualizações erradas; manipulação de dados (informações novas e recentes destinadas a enganar propositadamente).

Leite e Canto (2019) definem as notícias falsas como um conjunto alargado de técnicas de comunicação que envolvem sobretudo um apelo às emoções ou crenças individuais. Volkoff (2000) considera que a intenção de manipular a realidade, por alguns setores da comunicação social, está relacionada com a intenção deliberada de suscitar juízos de valor negativos e de ações concretas de condenação pública de agentes políticos e públicos. Num estudo alargado, que compreende 34 artigos académicos sobre esta temática, publicados entre 2003 e 2017, Tandoc, Lim e Ling (2018) estabelecem uma tipologia notícias falsas, que envolve conteúdos escritos num tom de paródia, sátira, bem como informações enviesadas, fotografias manipuladas ou ações de propaganda e relações públicas destinadas a contornar certas realidades.

Além destes breves aspetos conceptuais, a questão que subjaz a este artigo relaciona-se com uma vertente profundamente tecnológica. A internet desempenhou um papel importante na disseminação de notícias falsas (López-Borrull, Vives-Gràcia \& Badell, 2018; Roozenbeek \& Linden, 2018; Tandoc, Zheng \& Ling, 2017). Se recuarmos um pouco no tempo, novamente, e analisarmos o primeiro vídeo "viral" - como referiu a revista Wired (Veix, 2018), nos anos 80, em que um homem entediado na frente do computador o esmaga repentinamente - é possível verificar que se tratava de uma situação falsa. Ainda de acordo com esta publicação, as teorias da conspiração sobre este vídeo, intitulado "badday.mpg", inundaram os fóruns da Internet durante várias décadas: "à medida que a partilha de vídeos se tornou mais fácil e mais comum, outros filmaram as suas próprias versões e os vídeos tornaram-se num motivo de paródia. Era difícil não detetar uma manipulação na gravação, no momento em que se destruiu uma impressora num escritório". Este é um exemplo de como um mito urbano pode durar décadas. 
As notícias falsas agora estão perfeitamente inseridas numa sociedade pós-tecnológica (Cádima, 2018; Meneses, 2018). A tecnologia e as redes sociais concorreram decisivamente para um entendimento generalizado deste fenómeno das "notícias falsas" (Jankowski, 2018; Tandoc et al., 2017). Os aspetos mais preocupantes relacionam-se com as reais consequências que podem surgir com a consolidação de tais informações enganosas. Como Torres et al. (cit. em Meneses, 2018) lembram, "os bots do Twitter foram usados para repassar uma notícia falsa sobre a substituição do senador Ted Kennedy (...) [assim como] em 2014 com a promoção de uma história sugerindo a quarentena de todo um Texas devido à preocupação do Ébola em solo americano". No entanto, parece ser difícil identificar um período específico para essa tendência crescente, embora uma simples pesquisa no Google Trends indique que a campanha eleitoral presidencial dos EUA em 2016 desempenhou um papel importante nesse sentido (Leetaru, 2017). A mensagem é clara, em direção a esse chamado "infocalipse", conforme referiu Avid Ovadya, especialista nesta área e que trabalha na Universidade de Columbia, nos EUA. "Deveríamos ser capazes de desenvolver sistemas confiáveis e precisos que identifiquem claramente os vídeos falsos”, esclareceu.

Em maio de 2018, o jornalista Franklin Fouer escreveu este intrigante título num artigo da revista The Atlantic: "A era do vídeo falso começa". Neste sentido, apresentou exemplos de ferramentas digitais que conseguem manipular imagens e vídeos:

1. O software DeepWark permite que os utilizadores alterem a direção do contacto visual de alguém;

2. A empresa americana Nvidia criou um sistema capaz de alterar as condições climáticas em torno do vídeo;

3. O software Face2Face altera as expressões faciais;

4. Uma equipa de pesquisa da Universidade de Washington criou com sucesso um software 3D que alterou partes do discurso público de Barack Obama;

5. O Voco da Adobe agora é capaz de alterar partes do áudio, incluindo a introdução de várias expressões que não faziam parte do discurso original;

6. O Tacotron 2 do Google produz uma voz artificial muito próxima da humana;

7. O Ultimatte 2 manipula ambientes dentro dos vídeos.

Os recentes eventos associados à pandemia de Covid-19 colocaram ainda mais na agenda do debate público a centralidade da reflexão em torno de informações erradas. Aliás, recorde-se a este propósito que a própria Organização Mundial de Saúde 
(OMS) cunhou o termo infodemia, para designar o número crescente de conteúdos que, variando entre a imprecisão ou pura inverdade nos factos relatados, procuravam dificultar o trabalho dos jornalistas e condicionam a perceção pública sobre acontecimentos que marcam a atualidade. Esta é a nota dominante de um comunicado ${ }^{1}$ divulgado pela OMS, a 25 de agosto de 2020, a propósito da proliferação de conteúdos falsos sobre a pandemia de covid-19.

Patatt e Rocha (2020) sublinham um dado que demonstra eficazmente o interesse que a tecnologia tem vindo a demonstrar no combate à desinformação. De acordo com o relatório do Duke Reporter's Lab, citando dados de outubro de 2020, existiam cerca de trezentos projetos de verificação de factos divididos por mais de oitenta países, o que representava um acréscimo de cem iniciativas novas no espaço de um ano ${ }^{2}$. De qualquer modo, este artigo não defende que a sofisticação tecnológica irá determinar o fim da propagação de conteúdos problemáticos.

Para Deuze e Witschge (2017), o triunfo da vulgarização da ideia de "notícias falsas", que envolve um debate conceptual francamente mais auspicioso do que aquele que se encerra neste artigo, revela que o jornalismo deverá procurar o regresso, de modo mais eficaz e competente, a um dos seus baluartes históricos e eticamente situados e tidos como inquestionáveis: a (procura da) verdade.

\section{METODOLOGIA}

Este artigo pretende apresentar e descrever algumas ferramentas tecnológicas que oferecem uma ideia específica: existem esforços concertados de verificação de factos que se baseiam na multiplicação de técnicas digitais. Esta é provavelmente a nota mais ambiciosa de um ativo geral em relação a essas plataformas, mas, pelo menos, podemos entendê-las como tentativas, apreensões de esforços tecnológicos para combater notícias falsas. As referências teóricas e o enquadramento feito por diversos meios de comunicação social foram responsáveis pela popularização de algumas das plataformas mencionadas abaixo, a seguir.

1 Disponível em https://www.who.int/news-room/feature-stories/detail/immunizing-the-public-against-misinformation

2 Disponível em https://reporterslab.org/category/fact-checking/\#article-2781 
O Início de uma Nova Era?

Análise Exploratória a Plataformas Digitais de Verificação de Fake News

\section{Tabela 1}

Plataformas tecnológicas analisadas neste estudo

\begin{tabular}{c}
\hline Plataformas tecnológicas \\
\hline Checazap \\
Fátima \\
NewsGuard \\
Polígrafo \\
Snopes \\
\hline
\end{tabular}

Do ponto de vista da observação que subjaz a esta amostra não-probabilística (Quivy \& Campenhoudt, 1992; Lavrakas, 2008; Ayhan, 2014), construída por conveniência, seguimos o entendimento de Bengtsson (2016), que propõe modelos de análise de factos sociais e mediáticos com base em duas técnicas de análise: manifesta (o investigador retira conclusões a partir do discurso apresentado, numa análise tão próxima do texto quanto possível) e latente (o investigador avança para uma interpretação subjetiva do texto). Este artigo utiliza ambas formulações, uma vez que se dedica a analisar a informação concreta e visível nos sites das plataformas, ao mesmo tempo que desenvolve interpretações próprias a partir de trabalhos jornalísticos sobre o objeto de estudo representado. Deste modo, as perguntas de pesquisa que orientam este trabalho organizam-se em torno de duas perspetivas: como se podem caracterizar experiências de verificação dos factos, em plataformas tecnológicas desenhadas para esse efeito, em termos da dinâmica das próprias lógicas técnicas?

Neste sentido, esta amostra representa uma tentativa modesta de mapear algumas iniciativas tecnológicas a este respeito, uma vez que outras também podem ser incluídas. Esta análise exploratória foca-se em vários aspetos: equipa de trabalho; país em que a plataforma foi criada; missão e objetivos gerais; empreendimentos tecnológicos e requisitos técnicos; custos para os utilizadores.

$\mathrm{Na}$ Tabela 2, é apresentada uma visão geral das plataformas tecnológicas consideradas neste estudo: 


\section{Tabela 2}

Observação genérica das plataformas estudadas

\begin{tabular}{cccccc}
\hline Plataformas tecnológicas & Fundação & Staff & País & Ferramentas & Custos \\
\hline Fátima & 2018 & 9 & Brasil & Aplicação móvel & Grátis \\
Checazap & 2018 & 12 & Brasil & Site & Grátis \\
NewsGuard & 2018 & 35 & EUA & Plug-in no browser & Grátis \\
Polígrafo & 2018 & 16 & Portugal & Site & Grátis \\
Snopes & 1994 & 15 & EUA & Site & Grátis \\
\hline
\end{tabular}

\section{RESULTADOS E DISCUSSÃo}

Como já se referiu, este estudo não pretende representar a totalidade de experiências existentes nesse sentido. Utilizando os parâmetros de observação que constam da Tabela 2, procura-se descrever, sumariamente, a atividade genérica das referidas plataformas, como pretexto de ilustração da temática abordada em termos teóricos e que ensaia a questão da verificação de factos por intermédio de ferramentas tecnológicas. A maioria destas plataformas é exibida numa página web. Uma avaliação específica de cada iniciativa será apresentada seguidamente.

\section{Checazap}

O Checazap ${ }^{3}$ foi fundado em 2009 pelas jornalistas Amanda Rahra e Nina Weingrill, durante uma formação em jornalismo em Capão Redondo, um dos bairros mais violentos nos arredores de São Paulo, no Brasil. O principal ator dessa plataforma é o empreendedorismo social "Énois - Inteligência jovem”, uma organização dedicada a promover maiores oportunidades de discutir a importância do jornalismo entre os jovens. A equipa inclui doze membros que trabalham ao lado de estudantes de uma escola de jornalismo no Rio de Janeiro. O Checazap tem o seu próprio número do WhatsApp, permitindo que os cidadãos verifiquem se o conteúdo é verdadeiro ou falso. Semanalmente, especialmente à sexta-feira, o Checazap publica as informações

3 Disponível em https://enoisconteudo.com.br/checazap/ 
mais problemáticas partilhadas no WhatsApp, para que os cidadãos saibam o que foi compartilhado que é falso. Para esse resultado específico, o Checazap tem uma relação muito próxima com o monitor WhatsApp e a Open Society Foundation. Os utilizadores podem beneficiar dessas informações sem custos associados. Esta agência de verificação de factos possui informações atualizadas verificadas online ${ }^{4}$.

\section{Imagem 1}

Site do Checazap. Fonte: www.enoisconteudo.com.br/checazap/

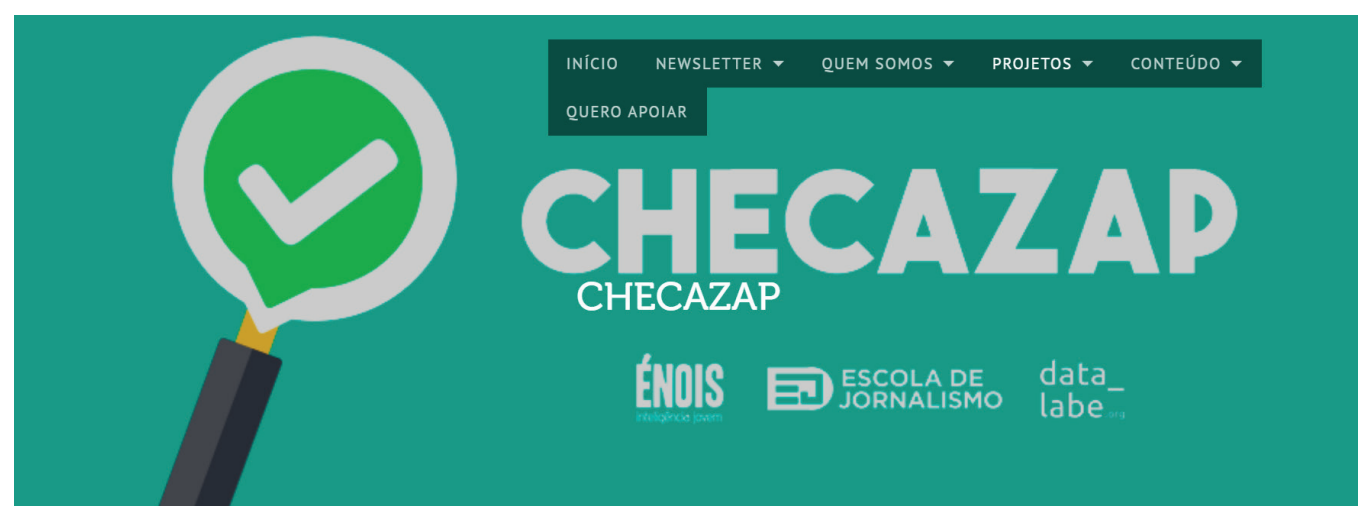

Em outubro de 2018, a $B B C$ deu conta que o WhatsApp estava a desempenhar um papel significativo na campanha presidencial brasileira: "Uma investigação da $B B C$ descobriu que os esforços para apoiar vários partidos e candidatos - cobrindo votos estaduais, federais e do Senado - usaram a técnica de mensagens em massa" (Magenta, Gragnani, \& Souza, 2018). Aparentemente, grupos políticos usaram software ilegal para atingir públicos específicos no Facebook, usando dados e contas pessoais. Milhões de brasileiros foram incluídos em grupos específicos do WhatsApp, onde foram partilhadas orientações ideológicas e políticas. Segundo as estatísticas fornecidas pelo site Statista, referindo-se a dados de finais de 2017, mais de metade da população do Brasil - cerca de 100 milhões - usavam o WhatsApp (Clement, 2019). Tendo em mente esses dados massivos, não é surpreendente encontrar uma ferramenta tecnológica para combater notícias falsas no WhatsApp.

4 Disponível em https://www.huffpostbrasil.com/author/checazap/ 
Em janeiro de 2019, a Recode.net perguntou: “O WhatsApp está a combater as notícias falsas, limitando a sua potencialidade viral. O Facebook e o Twitter poderiam fazer o mesmo?" . Muito pouco se sabe sobre isso, mas o WhatsApp aproximou-se um pouco, reduzindo a possibilidade de encaminhar mensagens: de 65000 para apenas 1280 pessoas (Wagner \& Mola, 2019).

\section{Fátima}

\section{Imagem 2}

Aplicação móvel Fátima. Fonte: www.aosfatos.org/fatimal

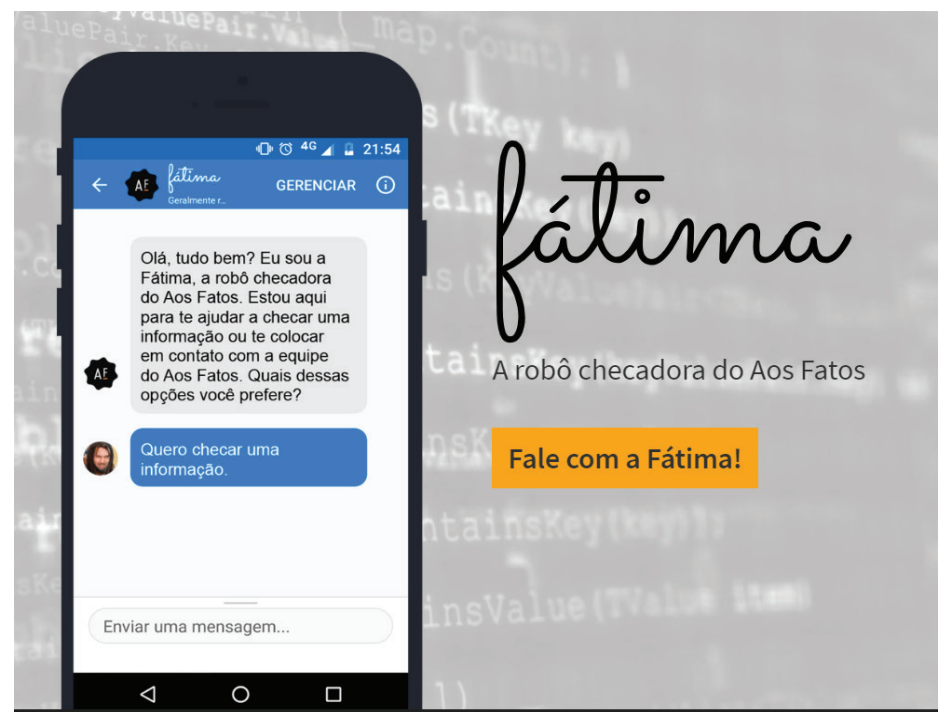

A empresa Aos Fatos decidiu criar um aplicativo móvel - Fátima ${ }^{5}$ - para ajudar os cidadãos na verificação de conteúdos falsos e enganosos. A equipa - principalmente jornalistas (9) - publica todos os dias uma lista completa das notícias mais relevantes dos média, dando-lhes um selo: verdadeiro; impreciso; exagerado; enganoso; falso. Esta avaliação decorre após várias etapas: 1) escolha de um tópico relevante nas notícias; 2) verificação da fonte original de informação; 3) procura de fontes de notícias confiáveis; 4) análise de declarações oficiais; 5) apresentação do contexto dessas

5 Disponível em https://aosfatos.org/fatima/ 
notícias. Após estas etapas metodológicas, os cidadãos podem procurar no robô da aplicação Fátima um esclarecimento sobre uma notícia ou tópico específico, com o carimbo específico.

Esta iniciativa surge após uma parceria entre a Aos Fatos e o Facebook, através de um projeto de alfabetização dos média financiado por esta empresa. Em abril de 2018, após apenas uma semana de trabalho intenso, o robot Fátima conseguiu identificar mais de 500 notícias falsas. O acesso a este serviço é gratuito (Fiore, 2018).

\section{Snopes}

\section{Imagem 3}

Site do Snopes. Fonte: www.snopes.com
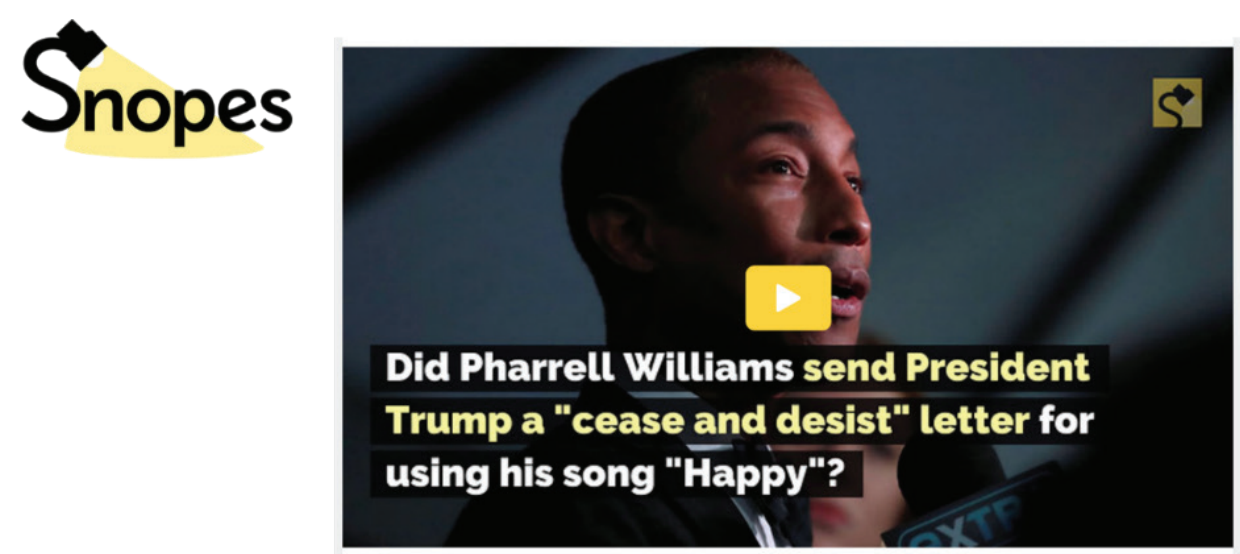

Did Pharrell Williams Send President Trump a 'Cease and Desist' Letter for Using His Song

Em janeiro de 2019, a Snopes decidiu interromper uma parceria de longo prazo com o Facebook. "Depois de contribuir com esse esforço por dois anos, queremos informar os leitores que a Snopes.com optou por não renovar a parceria com o Facebook", explicaram David Mikkelson, CEO da Snopes, e Vinny Green, vice-presidente de operações (Funke, 2019). Aparentemente, a Snopes discordou do Facebook quanto à definição do conceito de "notícias falsas". A empresa esclareceu que a forma como categoriza conteúdos falsos é complicada e morosa: "[o staff] precisa de inserir manualmente cada post falso para depois os sinalizarem numa plataforma. Esta opera- 
ção leva muito tempo para uma empresa que emprega apenas dezasseis pessoas e não tem uma sede física".

Apesar deste relacionamento tenso, a plataforma Snopes continua a ser um site adequado para fins de verificação de factos. Esta iniciativa constrói a "Hot 50 List", com as notícias falsas mais impactantes no espaço político dos EUA, e a seção "Vídeo" adiciona um tópico específico a essa análise, pois a maioria destas plataformas parece não identificar problemas com notícias que envolvam vídeos, principalmente da televisão ou dos média online. O Seattle Times descreveu a Snopes como o "site de desmistificação de fraudes mais popular da América" (Lacitis, 2018). De acordo com a plataforma de ranking de sites Similar.Web.com, a Snopes.com recebe mais de 32 milhões de visualizações por mês, a partir de computadores e dispositivos móveis, muito acima de seus concorrentes "The Straight Dope" (4 milhões) e FactCheck (3 milhões).

Embora esta análise cubra principalmente iniciativas recentes, a plataforma Snopes.com já conta com uma atividade longa, desde 1994.

\section{Polígrafo}

\section{Imagem 4}

Site do Polígrafo. Fonte: www.poligrafo.sapo.pt

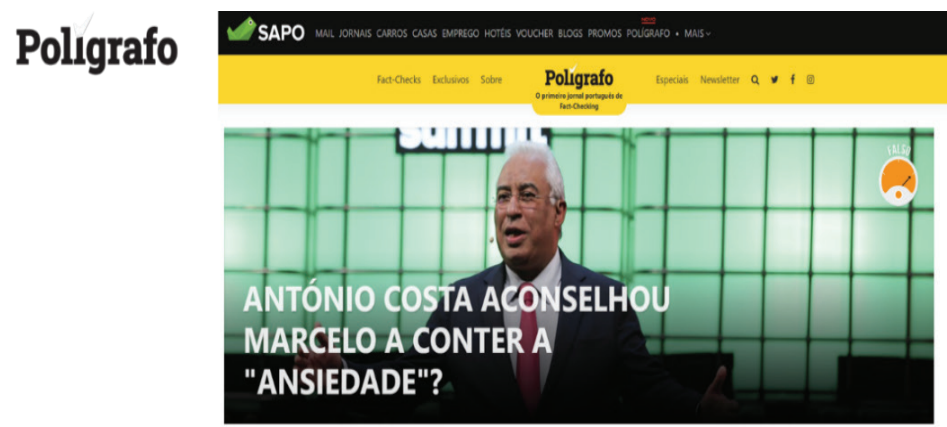

Fernando Esteves, o responsável editorial pelo Polígrafo, apresentou esta nova plataforma na edição de janeiro de 2019 da revista Jornalismo e Jornalistas (Clube de Jornalistas, 2019), uma publicação do Clube Português de Jornalistas: "Atualmente, a 
verificação de factos ocupa uma das áreas mais relevantes do jornalismo". O Polígrafo aborda notícias falsas, analisando principalmente declarações de responsáveis públicos, confrontando-as com ações e factos. Esteves define este projeto como "O Google da Verdade, onde as pessoas estão perfeitamente conscientes de que não encontrarão opiniões, mas factos, com base em documentos".

Esta plataforma foi apresentada na Web Summit 2018, realizada em Lisboa, Portugal. Naquela época, Fernando Esteves informou que as instituições públicas eram o principal alvo deste setor de verificação de factos. Diariamente, o Polígrafo publica até quatro histórias de verificação de factos. Esteves reconheceu que a eleição de Donald Trump, em 2016, acabou por ser o gatilho definitivo para a criação deste projeto.

\section{Newsguard}

\section{Imagem 5}

Site do Newsguard. Fonte: www.newsguardtech.com

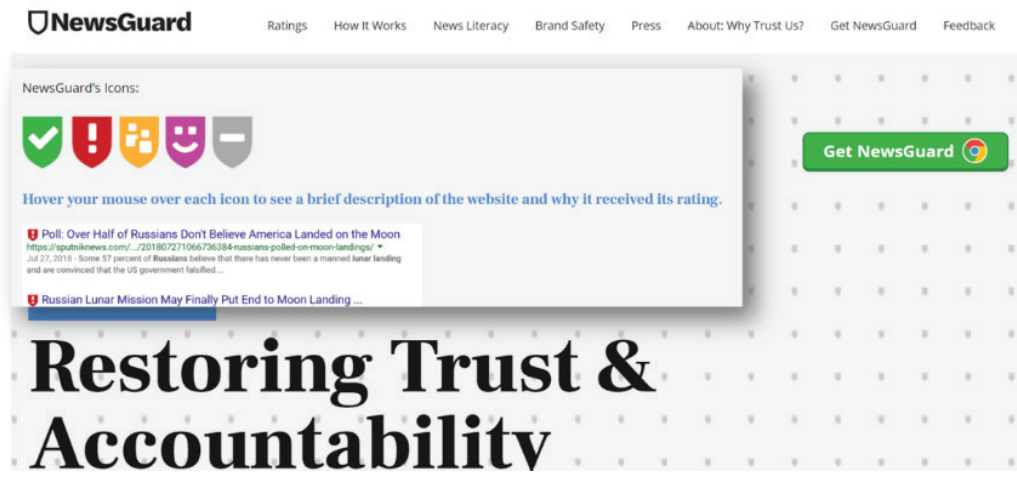

O Newsguard é totalmente diferente dos instrumentos de verificação de factos considerados nesta análise. Em primeiro lugar trata-se de um plug-in que facilmente se incorpora em qualquer navegador de internet. Foi desenvolvido para fornecer aos utilizadores um conjunto de informações valiosas em termos da veracidade dos conteúdos lá publicados: "se o site publica regularmente conteúdo falso, revela conflitos de interesse, divulga financiamento ou corrige publicamente erros de relatório". Os jornalistas do Newsguard revelam que nenhum algoritmo é usado para a validação de sites, pois cada um deles é avaliado com base em critérios que englobam nove escalas 
de fiabilidade dos dados. "Sempre que qualquer site não cumpre um dos nove critérios, enviamos um e-mail para que eles possam pronunciar-se sobre uma determinada questão. Os algoritmos não pedem comentários", diz o Newsguard online.

Este plug-in é, portanto, exibido junto aos links das notícias, de acordo com um conjunto de parâmetros: "Além dos ícones vermelhos e verdes dos sites de notícias e informações, o NewsGuard atribui um ícone azul a sites que publicam conteúdos gerados pelos utilizadores. Sites de humor ou sátira que imitam notícias reais recebem um ícone laranja de "sátira". Um ícone cinza indica que um site ainda não foi classificado pela equipe do NewsGuard".

Recentemente, esta plataforma chegou às manchetes ao decidir classificar a Fox News como "uma parte saudável de sua dieta de notícias". De acordo com o NiemanLab, esta avaliação levantou uma série de preocupações, principalmente sobre a independência desta plataforma, uma vez que as "teorias da conspiração" são exibidas regularmente neste canal de notícias (Benton, 2018). O Newsguard explicou que a Fox News foi categorizada com sucesso em todos os nove critérios, como "se assemelha à cobertura noticiosa mais tradicional".

\section{NOTAS FINAIS}

A atualidade tem vindo a demonstrar, de uma forma consistente e inequívoca, que o combate contra a disseminação de notícias falsas também passa pelo palco político. A este propósito, recorde-se que a Comissão Europeia anunciou, em janeiro de 2019, que cada Estado membro deve identificar um representante oficial para fornecer feedback sobre as campanhas de desinformação nos países e como foram abordadas. Em Portugal, o Ministério da Educação organizou uma iniciativa de âmbito nacional para realizar uma ação de formação específica nas escolas, ajudando estudantes e professores a lidar com abusos de informação e desinformação. Em coordenação com o Sindicato dos Jornalistas, estas sessões de treinamento incluem uma enorme variedade de cidades em todo o país e começaram em janeiro de 2019, em 40 escolas.

Este artigo reconhece a escassez de plataformas tecnológicas utilizadas numa amostra que procura, de um modo bastante simples, dar conta de uma parte evidentemente modesta de experiências de verificação de factos que existem. À medida que estes exemplos florescem, torna-se importante acautelar o estudo destas dinâmicas do ponto de vista da investigação. Aliás, estas plataformas fazem agora parte da Rede 
Internacional de Verificação de Fatos (International Fact-checking Network, em inglês), ligada ao Instituto Poynter, dos EUA, e que tem sido descrita como um esforço sólido para estabelecer atividades amplas e ambiciosas para promover a alfabetização mediática e noticiosa, a partir do tema das notícias falsas. Apesar de ser preverem resultados positivos sobre estas plataformas e iniciativas, parece ser ainda muito cedo para determinar se estas iniciativas se tornarão mais relevantes no futuro. No momento em que este artigo se debruça sobre esta questão, existem poucos relatos nos média sobre o sucesso/insucesso das plataformas anteriormente analisadas, o que indica que provavelmente o público e os cidadãos podem estar longe de conhecer esta realidade de base tecnológica.

Futuramente, a investigação nesta área poderá abordar a especificidade de cada país neste tópico do combate às notícias falsas. Sem qualquer intenção de representatividade, esta amostra pretendeu lançar alguma luz sobre uma realidade claramente escondida. Aparentemente, os académicos demonstram um interesse cada vez maior na reflexão sobre notícias falsas, mas falta claramente um estudo mais aprofundado sobre a forma como a tecnologia pode igualmente criar fundamentos técnicos para enfrentar e denunciar conteúdos falsos.

\section{REFERÊNCIAS}

Ahrens, J. (2018). Noam Chomsky: “La gente ya no cree en los hechos". https://elpais. com/cultura/2018/03/06/babelia/1520352987_936609.html

Albright, J. (2017). Welcome to the Era of Fake News. Media and Communication, 5(2), 87-89. https://doi.org/10.17645/mac.v5i2.977

Ayhan, H.Ö. (2011). Non-probability Sampling Survey Methods. In Lovric M. (eds) International Encyclopedia of Statistical Science. Springer, Berlin, Heidelberg. https://doi.org/10.1007/978-3-642-04898-2_41

Bengtsson, M. (2016). How to plan and perform a qualitative study using content analysis. NursingPlus Open, 8-14.

Benton, J. (2018). NewsGuard considers Fox News a healthy part of your news diet. http://www.niemanlab.org/2018/08/newsguard-considers-fox-news-a-healthypart-of-your-news-diet/ 
Bloch, M. (1912). Réflexions d'Un Historien Sur les Fausses Nouvelles de la Guerre. New York: Cambridge University Press.

Borges, L. (2019). Populismo, fake news e politicamente correcto: a relação entre a linguagem e os movimentos. https://www.publico.pt/2019/01/20/politica/ noticia/populismo-jornalismo-linguagem-1858649?fbclid=IwAR1vN_TDcndt BCk6Gc0Fu0oeWSxGY2g4aIpBx5Qa24kWhw2Uiz-lYNU3jkg

Cádima, F. (2018). A Rede na Estratégia da Aranha: “Pós-verdade”, Política e Regressão. Obs*, Special Issue, 21-36. https://doi.org/10.15847/obsOBS12520181294

Carvalho, M. (2018, dezembro). Kamil e as páginas que se salvam. Courrier Internacional, 274, 98.

Céu e Silva, J. (2019). José Gil: "O passado está a ser engavetado, digitalizado e virtualizado”. https://www.dn.pt/1864/interior/jose-gil-o-passado-esta-a-serengavetado-digitalizado-e-virtualizado-10396951.html

Clement, J. (2019). Share of population in selected countries who are active WhatsApp users as of 3rd quarter 2017. https://www.statista.com/statistics/291540/mobileinternet-user-whatsapp/

Clube de Jornalistas. (2018). Jornalismo \& Jornalistas, outubro/ dezembro. http://www.clubedejornalistas.pt/wp-content/ uploads/2019/01/JJ68.pdf?fbclid=IwAR0yZn3fb1gkUjz_n1pysN__ WUy7VobXQE350rQO3mQdx5YwVNGhRw4UI7Y

Comissão Europeia. (2018, 12 de março). Final report of the High Level Expert Group on Fake News and Online Disinformation. https://ec.europa.eu/digital-singlemarket/en/news/final-report-high-level-expert-group-fake-news-and-onlinedisinformation

Cordeiro, A. (2019). Fake news motivam Ministério da Educação a garantir formação sobre literacia nos media. https://www.publico.pt/2019/01/25/ sociedade/noticia/fake-news-motivam-ministerio-educacao-garantirformacao-literacia-media-1859397?fbclid=IwAR3y46M7nWXBAswPgoT-4a_ HM8YRxY7I7cBjnQvpWrzqzSBJ5gkZNu3sdtg 
Cram, I. (2019). Keeping the demos out of liberal democracy? Participatory politics, 'fake news' and the online speaker. Journal of Media Law, 11(2), 113-141. https:// doi.org/10.1080/17577632.2019.1697477

Deuze, M., \& Witschge, T. (2017). Beyond journalism: Theorizing the transformation of journalism. Journalism: Theory, Practice \& Criticism, 19(2), 165-181. https:// doi.org/10.1177/1464884916688550

Figueira, A., \& Oliveira, L. (2017). The current state of fake news: challenges and opportunities. Procedia Computer Science, 121, 817-825. https://doi. org/10.1016/j.procs.2017.11.106

Fiore, M. (2018). Aos Fatos lança bot que combate fake news no Twitter. https://www. b9.com.br/94276/aos-fatos-lanca-bot-que-combate-fake-news-no-twitter/

Funke, D. (2019). Snopes pulls out of its fact-checking partnership with Facebook. https://www.poynter.org/fact-checking/2019/snopes-pulls-out-of-its-factchecking-partnership-with-facebook/

Jankowski, N. (2018). Researching Fake News: A Selective Examination of Empirical Studies. Javnost - The Public, 25(1-2), 248-255. https://doi.org/10.1080/1318322 2.2018.1418964

Katsirea, I. (2018). "Fake news": reconsidering the value of untruthful expression in the face of regulatory uncertainty. Journal of Media Law, 10(2), 159-188. https:// doi.org/10.1080/17577632.2019.1573569

Kovarik, B. (2011). Revolutions in communication. Media history from Gutenberg to the digital age. Londres/Nova Iorque: Bloomsburry

Lacitis, E. (2018). Lies, lies and more lies. Out of an old Tacoma house, fact-checking site Snopes uncovers them. https://www.seattletimes.com/seattle-news/lieslies-and-more-lies-out-of-an-old-tacoma-house-fact-checking-site-snopesuncovers-them/

Lavrakas, P. J. (2008). Encyclopedia of survey research methods (Vols. 1-0). Thousand Oaks, CA: Sage Publications, Inc. https://doi.org/10.4135/9781412963947 
Leetaru, K. (2017, 17 de fevereiro). “Did Facebook's Mark Zuckerberg Coin 'Fake News'?”. Forbes. https://www.forbes.com/sites/kalevleetaru/2017/02/17/didfacebooks-mark-zuckerberg-coin-the-phrase-fake-news/\#35ff5a556bc4

Leite, L., \& Canto, F. (2019). Fake news e "viralização": responsabilidade legal na disseminação de desinformação. Revista Brasileira de Biblioteconomia e Documentação, 15, 143-156.

López-Borrull, A., Vives-Gràcia, J., \& Badell, J. (2018). Fake news, ¿amenaza u oportunidad para los profesionales de la información y la documentación?. El profesional de la información, 27(6), 1346-1446. 2018. https://doi.org/10.3145/ epi.2018.nov.17

Magenta, M., Gragnani, J., \& Souza, F. (2018). How WhatsApp is being abused in Brazil's elections. https://www.bbc.com/news/technology-45956557

Marinho, S. (2000). O valor da confiança nas relações entre jornalistas e fontes de informação. Cadernos do Noroeste, 14(1-2), 351-356.

Melro, A. (2019). O (des)interesse dos jovens pela atualidade: estudo sobre o papel dos media na informação sobre o mundo. Tese de doutoramento, Universidade do Minho, Braga, Portugal. https://repositorium.sdum.uminho.pt/ handle/1822/64830

Meneses, J. (2018). Sobre a necessidade de conceptualizar o fenómeno das fake news. Obs $^{*}$, Special Issue, 37-53. https://doi.org/10.15847/obsOBS12520181294

Parente, C. (2019). Observatório de media e imprensa - Espaços de participação e literacia mediática em Portugal e no Brasil. Tese de doutoramento. Braga: Universidade do Minho.

Patatt, C., \& Rocha, F. (2020). O fact-checking no Brasil e em Portugal: uma análise dos sites Agência Lupa e Polígrafo no combate às fake news relacionadas com o Coronavírus. Estudos de Jornalismo, nº 11, 6-20.

Quivy, R., \& Campenhoudt, L. (1992). Manual de investigação em Ciências Sociais. Lisboa: Gradiva. 
Rádio Renascença (2019). "Fake news". Portugal designa responsável pelo sistema de alerta da União Europeia. https://rr.sapo.pt/noticia/138092/fake-news-portugaldesigna-responsavel-pelo-sistema-de-alerta-da-uniao-europeia?fbclid=IwAR2 GHMZJ2BUCaav3GMWMVplq8I8Xlu31rdsy899atSvSysqiyMPHBqf0e2M

Ribeiro, V. \& Teixeira, P. (2018). Introdução - fake news num jornalismo dependente. Revista Portuguesa de História da Comunicação, 3.

Roozenbeek, J., \& Linden, S. (2018). The fake news game: actively inoculating against the risk of misinformation. Journal of Risk Research, 6(2). https://doi.org/10.108 0/13669877.2018.1443491

Tandoc Jr., E., Zheng, L., \& Ling, R. (2018). Defining “Fake News", Digital Journalism, 6(2), 137-153. https://doi.org/10.1080/21670811.2017.1360143

Veix, J. (2018). The Strange History of One of the Internet's First Viral Videos. https:// goo.gl/B7nu8N

Volkoff, V. (2000). Pequena História da Desinformação: do cavalo de Tróia à Internet. Cruz Quebrada: Editorial Notícias.

Wagner, K., \& Molla, R. (2019). WhatsApp is fighting fake news by limiting its virality. Could Facebook and Twitter do the same? https://www.recode. net/2019/1/25/18197002/whatsapp-message-limit-fake-news-facebook-twitter

Wardle, C., \& Derakhshan, H. (2018). Thinking about 'information disorder': formats of misinformation, disinformation, and mal-information. In C. Ireton, \& J. Posetti (Eds.), Journalism, fake news \& disinformation: handbook for journalism education and training (pp. 44-55). Paris: UNESCO. 